\title{
Ambiguity as a Strategy for Negotiating Identity
}

\author{
Anbjørg Ohnstad \\ Oslo and Akershus University for Applied Sciences \\ Department of Social Work, Child Welfare and Social Policy \\ Anbjorg.Ohnstad@hioa.no
}

\author{
Keywords: \\ ambiguity \\ ethnicity \\ sexuality \\ identity \\ marginalization
}




\begin{abstract}
The article explores the relationship of ambiguity to identity in societal contexts dominated by discourses of fixed, essentialist and hierarchic sexual and ethnic dichotomies. Rather than accept hegemonic definitions of ambiguity as something harmful to society and its members, the article suggests that ambiguity functions as a key coping strategy especially for women and men navigating, negotiating and positioning themselves and their identities in opposition to how they are defined by heteronormative and Eurocentric discourses. Drawing on data collected from psychotherapeutic practice as well as from interviews with women and men who have used ambiguity in this way, the article describes how they define and celebrate their identities in opposition to the stigmatized and subordinate identities ascribed to them by dominant binary discourses in a social field marked by rigid boundaries, uncertainties and paradoxes. The article concludes with a brief discussion of the importance of ambiguity as a strategy not only for aiding interpersonal relationships but also as one crucial in organizational contexts.
\end{abstract}


In this article, I will explore the concepts of ambiguity and identity - and especially the use of these concepts to understand people maneuvering in a field filled with different cultural discourses. My main interest as a psychologist has been to explore how identities develop among women and men navigating through sociocultural contexts dominated by oppressive gender and ethnic discourses, and how these people use various elements from these contexts to maintain feelings of self-worth. I have no special expertise when it comes to oppressive Eurocentric discourses, but I think that some of what I have found in my own clinical work with women struggling to define their own identities against dominant heteronormative discursive formations may have some usefulness when applied to members of ethnic groups subject to similar marginalizing discourses.

\section{Background for the article}

Much of my practice as a clinical psychologist has involved therapeutic work with women living with other women. In this paper, I use examples from my practice to illustrate how women with this sexual orientation have employed ambiguity in dealing with dilemmas arising in their common quest to say who they are in social contexts that often stigmatize, marginalize, and exclude them. The paper also draws on data from university students who tell of similar experiences of stigmatization and marginalization. As an associate professor teaching in a school of social work, I have supervised a number of students whose master's theses provide examples of dilemmas and problems experienced by members of sexual and ethnic minorities using ambiguity in struggling to gain a positive sense of themselves in opposition to the stigmatizing effects of dominant ideologies. Their unique tales of their lives, presented in a way to preserve their anonymity, provide glimpses of universal themes in their coping strategies.

\section{What is ambiguity?}

The dictionary defines ambiguity as something not having a single clear meaning; it is something or some act liable to more than one interpretation (Collins, 2003). In my clinical practice and research, I have found ambiguity to be a personal coping strategy that allows for movement between categories of identity, especially those requiring navigation and negotiation in social contexts dominated by gendered dichotomies of, for example, normality/ deviance, heterosexuality/homosexuality, and masculine/feminine. In relation to ethnicity in Norway, this kind of maneuvering may also function as a way of coping with dilemmas involving the dominant ideological dichotomy of Norwegian/foreigner. Ambiguity, as described above, functions to create space for growth and authenticity by challenging fixed and hierarchical binaries that lock sexual, ethnic and religious diversities into rigid polar opposites (Ohnstad, 2009a, p. 58).

As a coping strategy, ambiguity represents a much less arduous and much more considerate way of navigating and negotiating one's identity than other more confrontational ways of defining oneself. The Norwegian sociologist Dag Østerberg (1993) introduced the concept of amphibian behavior having particular relevance to ambiguity as a coping and identity defining strategy. Amphibians, of course, are creatures who live in water as well as on land. In much the same way, minorities have to move in different cultures and understand different social codes and use them.

Ambiguity, too, may be understood as an expression of ambivalence - especially with regard to inner conflicts involving shame as well as disgust for having inappropriate and taboo feelings, and experiencing oneself as an object for society's contempt. These and related feelings of stigmatization and subordination often make interaction with other people difficult because all of us move in social and cultural landscapes where dominant 
discourses set the premises for what is acceptable and unacceptable, as well as for which persons belong to the majority and which do not.

From therapeutic literature, we know that tolerance for ambiguity is of great value for professional helpers (Reichelt \& Rønnestad, 1999). To be a good helper, one needs to understand and recognize the other person on her premises. This entails being open to her feelings and values. Professional helpers must learn to tolerate discomfort and to set their own feelings and values aside to create a safe and secure space for the stories of those seeking their help (Danylchuk, 2015; Reichelt \& Rønnestad, 1999; Rober \& Seltzer, 2010).

History has shown that ambiguity can be both a resource and a personal strategy allowing movement between binary gendered identity categories (Butler, 1991; Ohnstad, 2009a). In describing what she sees as the subversive character of this kind of movement, Judith Butler observes

If 'existing' one's gender means that one is tacitly accepting or reworking cultural norms governing the interpretation of one's body, then gender can also be a place in which the binary system restricting gender is itself subverted. Through new formulations of gender, new ways of amalgamating and subverting the oppositions of 'masculine' and 'feminine', the established ways of polarizing genders becomes increasingly confused, and binary opposition comes to oppose itself. Through the purposeful embodiment of ambiguity, binary oppositions lose clarity and force, and 'masculine' and 'feminine' as descriptive terms lose their usefulness. Inasmuch as gender ambiguity can take many forms, gender itself thus promises to proliferate into a multiple phenomenon for which new terms must be found (1986, p. 48).

As Pepper Schwartz has pointed out, ambiguity creates considerable distress for a great many people in society precisely because it subverts the accepted systems of categorization. As she puts it,

In general, we hate that someone is not firmly assigned to a body type and look that telegraphs both gender and sexuality. In fact, it occurs to me that this intolerance of gender ambiguity may be one of the reasons our society hates fat people. Fat pads out physical differences between the sexes; the roundness we associate with women covers both men and women who are fat: breasts and chests look alike. . . and facial contours become similar. . . . [A]ll kinds of gender ambiguity . . . has been historically grounds for severe punishment including death, in some countries and during certain periods of history (2008, p. 85).

To use ambiguity as a successful personal strategy, persons marginalized and stigmatized by dominant discourses first need to know the social context and the social codes. History has also shown that ambiguity allows individuals and groups to use elements from different social contexts to define themselves and in this way often change the official and dominant discourse over time (Bourdieu,1998/2000). In Norway, one of the most recent illustrations of this is provided by organizations advocating equal rights for gays and lesbians, who made use of pre-existing and strong egalitarian values in Norwegian society, for example, to combat job discrimination and to legitimize same-sex marriage (Ohnstad, 2009b). Currently, various immigrant organizations - especially those representing Muslims - are involved in similar processes in the struggle for acceptance of their ethnic and religious identities by mainstream Norwegian society (Narvesen, 2013).

In earlier research focused on how women living with other women shaped and maintained feelings of self-worth about themselves, I found that ambiguity played a central role for them as they maneuvered their ways through a social context dominated by heterosexual 
norms (Ohnstad, 2009b). Another more recent example is represented by women and men with Muslim backgrounds living gay and lesbian lives in the West who often encounter great difficulties in navigating between strict moral discourses from their homelands and those reflecting more liberal views of homosexuality in their host countries (Narvesen, 2013). Living gay and lesbian lives often requires them to make some parts of their lives invisible to families and relatives. One of my master's students, who interviewed gays and lesbians from families with Muslim backgrounds, found that they attempted to navigate in this turbulent landscape by separating the stories about themselves from the past (Narvesen, 2013). Thus, a Muslim man living together with and married to another man in Norway does not tell his parents in Pakistan about this part of his life. He does not dare to speak of this for fear that the family will either exclude him or find him a wife in Pakistan. To navigate through the complicated landscape created by this binary existence of being the son in a traditional Pakistani family as well as being a man married to another man in Norway creates a series of dilemmas for him. First and foremost, these impact heavily on his sense of identity. But in order to examine this in detail we are required to look at how identity may be defined.

\section{What is identity?}

In today's social and behavioral sciences, it is common to think of identity as involving fluid processes of presenting oneself in different ways. As Douglas Kellner puts it, "identity today becomes a freely chosen game, a theatrical presentation of the self, in which one is able to present oneself in a variety of roles, images and activities"(1992, p. 157). Further emphasizing understandings of identity as processual, Charles Taylor introduces the notion of dialogic identity:

We define our identity always in dialogue with, sometimes in struggle against the things our significant others want to see in us. Even after we outgrow some of these others-our parents, for instance-and they disappear from our lives, the conversation with them continues within us as long as we live (1994, p. 32-33).

On the other hand, some argue that rather than a way of becoming, identity can be viewed as a stable way of being in the world (Hall 1998, p. 225). At certain times, solid and fixed identity categories or essentialist identities are often important for some groups in society. In recent times, for example, it has been important for women, gays and lesbians and many minorities to be perceived as belonging to special categories. Black Power, Black is Beautiful and Gay Pride are all recent illustrations of this kind of identity positioning - often referred to as strategic essentialism (Spivak, 1996). Members of groups whose marginalization, stigmatization and subordination in society have been legitimized by hegemonic discourses have enhanced their identities greatly by employing essentialist definitions to put their rights on display and to define themselves rather than be defined by dominant discourses. This is what we may call identity politics and it has been of great value for many groups and individuals (Juhila, 2004). Identity politics is anchored in fixed categories - with great emphasis on positive meanings of difference (Juhila, 2004). Minorities - and even oppressed majorities - can make use of stereotyped identities in order to be recognized by others. At the same time, however, identity politics can be a double-edged sword: while useful to a group as a whole, stereotyping also possesses the potential for harming a particular individual's sense of self, since the stereotype allows only a few of the many facets making up one's identity to be seen.

It also needs to be noted that there exist many interpretations of identity, such as cultural identity, individual identity, and sense of self and self-worth. In pointing to these complexities, Jeffrey Weeks observes, 
Identities are not neutral . . . By saying who we are, we are also striving to say what we are not, what we believe and what we desire. The problem is that these beliefs, needs and desires are patently in conflict, not only between different communities, but also within individuals themselves (1998, p. 89).

In terms of gender politics, identity may also be understood as much influenced by the dominant heterosexual norm: one positing gays and lesbians, for example, as the sexual "other", as Jane Ussher (1997) has put it. Steven Seidman (2013) argues that the concept of the Other must be distinguished analytically from that of "difference". If the latter speaks of patterns of social disadvantage, then otherness is fundamentally about cultural denigration and exclusion. As I understand this differentiation of otherness, it underscores potential dangers to the social order. For example, left-handedness represents a kind of difference not dangerous for the social order, while otherness defined in relation to ethnicity and sexuality represents a much greater danger to the social order. For example, an identity as a gay Muslim represents a threat to the Islamic social order because it directly challenges the traditional heteronormative order of men and women.

One definition shared by Jerome Bruner (1990) and Carolyn Saari (1993) sees identity as a personal meaning system created over the course of an individual's life experience in the world. This system of meanings is organized primarily in a narrative form. In other words, identity is constructed upon the stories or narratives we tell about ourselves. These stories provide us with the experience of continuity. Given the hegemony of heteronormative framings in society, gay and lesbian clients who seek help at welfare agencies, for example, need to trust in the probability that their stories will be recognized as important even before they begin telling them. At the same time, they need to be provided with a safe and nonthreatening space for discussing questions and issues involving their own vulnerabilities, which easily can be misinterpreted and misunderstood.

One set of possible misinterpretations for gays and lesbians may involve perceptions of their feelings of being inauthentic in social contexts that see homosexuality as a general relationship problem connected to pathology (Cullberg, 1999). Another source of misunderstanding might be perceptions of their appearance as gender deviants and perhaps indicative of problems they may have had in relationships with the opposite gender. If misconceptions of this sort narrow the therapeutic space, little room is left for clients to voice their worries with professional helpers. Clients are often silenced in this way in situations where helpers are unaware of how they are influenced by hegemonic norms and of the power they possess in these encounters (Ohnstad, 2005).

Identity understood as "storying" is also related to the story of our life in the past, the present and the future. We all try to achieve continuity between the past, the present and the anticipated future. For some marginalized peoples, however, it is extremely difficult to realize continuity from past to present when the past is something they wish to flee from or erase from their memories. This is often the case for those who have been tortured or who have experienced traumatic incidents in their childhoods (Varvin, 2008). This condition often makes it hard for them to see any possibilities for their lives in the future. In describing this condition and pointing out its contrast to identity crises, the American cultural anthropologist Jules Henry pointed out that

Identity loss . . . must be distinguished from a crisis of identity in one who is hesitating among available choices and has made no decision yet. The second type of identity problem has a future; the first is rooted in the past. When an adolescent says, 'I don't know who I am,' we have to discover whether he means he can't 
make up his mind what he will do with his life, or whether he does not know what has been done to his life $(1971$, p. 106)

Identity understood as a system of narratives involves those stories which we share with others, those which cannot be shared, those about which one is ashamed, as well as those which do not fit into a new context. Stuart Hall (1998) writes that identity consists of an invention formed at the unstable meeting point of countless stories of subjectivity and the stories of history and culture.

In the introduction to their 1992 book, Storied Lives: The Cultural Politics of SelfUnderstanding, Rosenwald and Ochberg made the point that "culture speaks itself in" our stories. Culture, seen from this kind of perspective, may also be seen as providing narrative resources for identity that are strongly shaped by gender, social structure, and the material and ideological givens of a particular society. Especially in terms of power, people may become marginalized by different binary cultural discourses requiring them to navigate through uneven playing fields rigidly marked by rigid discursive divisions between masculinity and femininity, heterosexuality and homosexuality, and native and foreign ethnic groups. These polar opposites erase the multitudes of variation found among the individuals making up these groups and lump them together into fixed dichotomies with the normative center on one side, and the deviant and marginalized other on the other side.

To illustrate the difficulties for one's identity in navigating between ethnic discourses and sexual discourses I will use a story from my clinical practice.

\section{Mehru's story}

Mehru was born in Norway where her parents lived after emigrating from Africa in the 1970s. Her father presents himself as a social worker, a proud African man and a political radical. Her mother is a teacher and works in a kindergarten. Mehru has a brother, and an uncle she calls brother. The family have strong attachments to each other. When Mehru found that she was more sexually attracted to women than men, she had to break some of the tight bonds to her family. She knew the family's strong connection to both African and Christian traditions would never permit them to accept her identity as a lesbian. They could accept her partner as a woman friend but not as a lover. This makes Mehru sad because she misses her family, but she refuses to give up her lover, so she has to navigate in this landscape as best she can. This is difficult for her - especially in communicating with her father. They share many of the same values when it comes to political and social engagement, but his hostility towards sexual minorities is so aggravating to Mehru that she tries to reduce her contact with him to a minimum. Thinking of having a baby makes her dilemmas even more complicated. How can she have a family with a grandfather for her baby who refuses to accept her partner?

Impacting on Mehru's life is a complex of crosscutting discourses of sexuality, ethnicity, gender and traditional notions of masculinity and femininity. The African discourse of gender with its immovable binary of masculinity and femininity is on a collision course with the Norwegian discourse of a liberated view of same-sex attraction. Mehru is required by loyalty and love for both her partner and her parental family to navigate and negotiate her identity on the battlefield shaped in great part by these conflicting discursive formations. She spends much time and effort in maneuvering herself in ways that permit her to avoid excessive confrontations, and this causes her much pain and many worries - especially about the future. In one way, her experiences as well as those of other clients I met in the therapy room can be summed up as representing many facets of discomfort. This term describes a situation of not fitting in or being dissatisfied with one's situation. 
A keystone in the ideologies of many gay and lesbian organizations in recent decades has been the insistence that persons attracted to the same sex ought to "come out" and make their desires known in all contexts. This has been a successful strategy for identity politics in many contexts, but on a more individual level coming out can be perilous for a gay or lesbian person who has grown up in a traditionally religious family, be they Muslim or Christian. Also, continuously emphasizing one's identity everywhere in this way can be extremely demanding.

\section{Fixed identities}

These kinds of uncomfortable and demanding situations often occur when we encounter people who do not "fit" into our categories. They are ambiguous: "maybe yes this person is a man", "maybe no the person is a woman". There are currently heated discussions in Sweden and Norway about using the non-gender-specific pronoun "hen" instead of "he" (han in Swedish and Norwegian) or "she" (hon in Swedish and hun in Norwegian). The idea of using non-gender-specific pronouns is disturbing to many people but even more disturbing for the social order. It can be difficult to achieve tolerance for ambiguity and people who do not fit into clear categories. This is especially so in the case of minorities whose failure to "fit" can result in stigmatization, distrust and even disgust among members of the majority. For marginalized people required to deal with these processes, the ability to navigate is therefore of great importance in helping them take care of themselves, their feelings of self-worth and their ability to successfully challenge dominant norms.

As professional workers in the welfare state, we must reflect more on ambiguity and issues related to it: we need to learn more about what we do not understand, why we do not understand and how we can learn to understand more. Central to these processes of understanding is the ability to be patient and to avoid putting others in fixed categories. We must also be open to what we do not understand and willing to learn more from the other. Tolerance for ambiguity is a quality demanding that we be open to other people who are between and betwixt the fixed categories.

Let me give an example. This is a story told by a professional childcare worker who began reflecting on her experiences with a family fostering a boy named Amir. There had been trouble in his own family because of Amir's aggression against his sister and other females. His ethnic Norwegian foster mother had addressed this problem and seen it as involving Amir growing up to be "an Iraqi man". Initially, both the foster mother and the child welfare worker shared a project of integrating Amir into a Norwegian context: their goal was for Amir to be Norwegian. In line with this goal for Amir, they associated his negative behavior with his ethnic background. In short, both the professional and the foster mother defined the problems of his personal behavior as the problem of his parental culture. His violence against his sister became a storyline of a dominant discourse for identity (Spydevold, 2014, p.166-122). Yet, in reflecting over this, the childcare worker began to see how she and the foster mother had handled the problem without reflecting on their own culture where such things as quarrels between brothers and sisters are commonplace and where little boys don't always follow orders from their mothers and teachers. The childcare worker then began to see that Amir's identity had been looked upon and interpreted based on a fixed, stereotyped and stigmatized category for how Iraqi men are expected to behave. However, by using a more ambiguous identity concept and listening closely to Amir's story of his situation and gaining a broader view of his family's life situation, she came to understand that there were other reasons for his behavior. Amir might be trying, for example, to use his behavior as a means of connecting with his past, which did not "fit" the Norwegian context. In addition, she could see, for example, that Norwegian boys of Amir's age could also act aggressively towards their sisters and other females. In this particular case, the 
professional fortunately reflected enough on her own practice to begin to see that it had been too narrow and too confined to one frame of reference. In short, she began to see that it helped to go outside her comfort zone and allow for more ambiguity in her understanding of what she was observing and interpreting.

Steven Seidman (2013, p. 20) puts the dilemmas of fixed and ambiguous identity as follows:

There are powerful psychological and social forces aligned to fix and manage the category of the Other and the actual population of hated selves. The aims to protect the symbolic and social division between the defiled and the civil, along with divisions and rankings internal to this binary. As we know, the making of populations of the Others sustains normative statuses and social hierarchies. For example, the other side of defiling of homosexuality and blackness has been the purification and civil empowering of heterosexuality and whiteness. Hierarchies of status, wealth and power pivot around a politics of exclusions and making of otherness. This is the dark side of social life. And yet, as we know from recent politics of identity, the category of the Other is unstable and contestable.

\section{Discussion and conclusion}

This article has briefly examined the concepts of ambiguity and identity as well as some of their connections. Although the focus on ambiguity as a way of navigating and negotiating one's identity in complex social fields has been framed using perspectives from clinical psychology and social work, it should be noted that organizational researchers since the 1980s have been much concerned with showing similar benefits of ambiguity in institutional contexts (Eisenberg \& Whitten 1987). Although not directly addressing the role of ambiguity in identity-work, Eisenberg and Whitten (1987) argued that ambiguity offered benefits as a means of non-disclosure within organizations. In so doing, they challenged what they described as "deeply held beliefs about human relationships" calling for open communication ( $p .420$ ). They argued that contrary to such belief systems, clear and open communication about what one thinks and feels may often have destructive consequences in groups. This kind of openness, they stated, "may be inappropriate since such disclosure provides a rallying point for the opposition ...." (p. 423). Introducing what they described as "strategic ambiguity," Eisenberg and Whitten further claimed that this kind of a vague communication style, in which speech is open to more than one interpretation, and meaning is extremely difficult to pin down, was well suited for attaining what they termed "multiple interactional goals" (p. 422). If one applies this organizational view of ambiguity to the situations faced by Mehru and the gay son of the Pakistani family discussed earlier, there are a number of obvious parallels, including avoidance of full disclosure and use of ambiguity as means of managing interactions in such ways as to avoid causing pain to others or oneself.

This view of ambiguity and its uses underscores one of the lessons drawn from my clinical practice. Namely, that in working with women and men who are attracted to the same sex, one sees time and again that intergenerational communication is often extremely tough because interactions are often painful. In such challenging landscapes, ambiguity has the potential for lessening the pain and helping the client maintain some semblance of positive communication with parents and other members of extended families.

In the case of the child welfare professional, we saw that she was so blinded with her own rigid and non-reflective attitude toward her own culture and stereotyped views of the ethnic 
"other" that she failed to see her client as a whole person. The dichotomous ethnic discourse of native/foreigner created a range of problems in what could have been a helping rather than a harmful relationship. Had it not been for the childcare professional's reflection on the discursive cultural formation dominant in her own life, the relationship was likely to have produced pain and discomfort for a number of persons in addition to the boy.

Finally, this paper has attempted to show some of the ways in which women and men marginalized and excluded from many social fields have used ambiguity in navigating through spaces dominated by rigidly defined gender and ethnic binary discourses. In this way, they have also done their bit in subverting hegemonic norms. According to Steven Seidman (2013), the other as the sexual or ethnic other represents a major threat to hegemonic norms - especially as we have witnessed in Norway and elsewhere where rather than trying to survive as isolated and stigmatized individuals, such persons have united in organizations pursuing political and related goals in opposition to hegemonic discursive formations.

To sum up I think the relationship of ambiguity and identity can be used in analyzing how marginalized people manage to maneuver their ways through contexts often dominated by strong opposing and binary discourses. And in so doing, they manage to maintain a sense of their own self-worth and integrity in a social field dominated by rigid boundaries and categories, uncertainty and paradoxes.

\section{Acknowledgements:}

Many thanks to Professor Michael Seltzer who has helped me with the language and made very useful comments about the article. 


\section{References:}

Bourdieu, P.(1998/2000). Den masculine dominans (Masculine dominance) (K.S.Johansen, trans). Paris/ Oslo: Éditions de Seuil/ Pax

Bruner, J. (1990). Acts of meaning. Cambridge: Ma Harvard University Press

Butler, J. (1986). Sex and Gender in Simone de Beauvoir's Second Sex, Yale French Studies. Simone de Beauvoir: Witness to a Century. No. 72, pp. 35-49, Winter.

Butler, J. (1991). Imitation and gender subordination. In D.Fuss (ed).Inside/out. Lesbian theories, gay theories (13-32). New York: Routledge

Collins (2003) English Dictionary. Leicester: Harper Collins Publisher

Cullberg, J. (1999). Dynamisk psykiatri. (Dynamic psychiatry) Oslo: Tano A/S

Danylchuk, L. (2015). The training of trauma therapist: Bringing it home. Journal of Trauma \& Dissociation. 16, 1-6 http://dx.doi.org/10.1080/15299732.2014.930804

Eisenberg, E. \& Witten, M. (1987). Reconsidering Openness in Organizational Communication, The Academy of Management Review 12 (3) 418-426 http://dx.doi.org/10.5465/AMR.1987.4306557 http://dx.doi.org/10.2307/258509

Hall, S. (1998). Cultural Identity and Diaspora, in J. Rutherford (Ed.) Identity: Community - Culture - Difference.(222-237). London: Lawrence and Wishart

Henry, J. (1971). Pathways to Madness. New York: Random House.

Juhila, K. (2004).Talking back to stigmatized identities: Negotiation of culturally dominant categorizations in interviews with shelter residents. Qualitative Social Work. Aug 27, 2004, 239-275 http://dx.doi.org/10.1177/1473325004045665

Kellner, D. (1992). Popular Culture and Constructing Postmodern Identities, in Lash, S. and Friedman, J. (eds.) Modernity and Identity. (141-178) Oxford: Blackwell.

Narvesen, R.R. (2013). A navigere som lesbisk, homofil og bifil med muslimsk bakgrunn i det heteronormative farvannet.(To navigate as lesbian, homosexual, and bisexual with a muslim background in the heteronormative water) in A. Backe Grønningsæter, H. W. Kristiansen, B. Lescher-Nuland (ed), Holdninger, levekår og livsløp - forsking om lesbiske, homofile og bifile. (Attitudes, living conditions and career - research in lesbian,homosexuals and bisexuals) Oslo: Universitetsforlaget.

Ohnstad, A. (2005). Speaking vulnerable issues into exisrence: Their consequenes for psychotherapy. Scandinavian Journal of Public Health, 33, 1-5 http://dx.doi.org/10.1080/14034950510033336

Ohnstad, A. (2009) a. Lesbiske identiteter - skeive bevegelser (Lesbian identities queer politics). Unpublished doctoral dissertation. Faculty of Psychology. Oslo University.

Ohnstad, A. (2009) b. If I am not straight or gay, who am I. Clinical Social Work Journal 37, 357 - 367 http://dx.doi.org/10.1007/s10615-009-0210-8

Reichelt, S.\& Rønnestad, H. M. (1999). Psykoterapiveiledning. (Supervision in psychotherapy). Oslo:Tano Aschehoug 
Rober, P.\& Seltzer, M. (2010). Avoiding Colonizer Positions in the Therapy Room: Some Ideas About the Challenges of Dealing with the Dialectic of Misery and Resources in Families. Family Process. Vol. 49 (1), 123-137.

http://dx.doi.org/10.1111/j.1545-5300.2010.01312.x

Rosenwald G. C.\& Ochberg, R. L. (1992). Storied Lives: The Cultural Politics of SelfUnderstanding, New Haven: Yale University Press

Saari, C. (1993). Identity complexity as an indicator of health. Clinical social work, 21, 11-21 http://dx.doi.org/10.1007/BF00754909

Schwartz, P. (2008). The Social Construction of Heterosexuality in M. Kimmel (Ed), The Sexual Self: The Construction of Sexual Scripts. pp 80-92. Nashville, TN: Vanderbuilt University Press

Seidman, S. (2013). Defilement and disgust: Theorizing the other. American Journal of Cultural Sociology. Vol.1, 3-25 http://dx.doi.org/10.1057/ajcs.2012.3

Spivak, G. C. (1996). The Spivak Reader: Selected works of Gayatri Chakravorty Spivak, New York: Routlegde

Spydevold, M. Fordommer i barnevernfaglig praksis, In Ohnstad, A.; Rugkåsa; M.; Ylvisaker, S. (2014) Ubehaget i sosialt arbeid (Social work and its discontent), (116122)Oslo, Gyldendal Akademisk,

Taylor, C. (1994). The Politics of Recognition, in Gutman, A. (Ed.) Multiculturalism. (25-74) Princeton, NJ: Princeton University Press.

Ussher, J. M. (1997). Framing the sexual "Other": The regulation of lesbian and gay sexuality. Body talk: The material and discursive regulation of sexuality, madness and reproduction. London/New York: Routledge

Varvin, S. (2008). Flyktningepasienten, (Patient of refugee).Oslo:Universitetsforlaget

Weeks, J. (1998). "The Value of Difference," In Jonathan Rutherford (Ed.) Identity: Community - Culture - Difference, (88-100). London: Lawrence and Wishart

Østerberg, D. (1983). Fortolkende sosiologi (Interpretative sociology). Det blå bibioteket. Oslo: Universitetsforlaget 